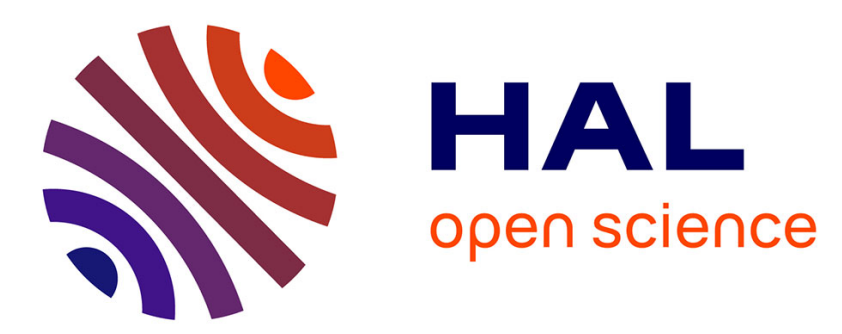

\title{
Thermal modeling and optimization of microalgal biomass production in the harsh desert conditions of State of Qatar
}

\author{
Jeremy Pruvost, V. Goetz, A. Artu, P. Das, H. Al Jabri
}

\section{To cite this version:}

Jeremy Pruvost, V. Goetz, A. Artu, P. Das, H. Al Jabri. Thermal modeling and optimization of microalgal biomass production in the harsh desert conditions of State of Qatar. Algal Research Biomass, Biofuels and Bioproducts, 2019, 38, pp.101381. 10.1016/j.algal.2018.12.006 . hal-02152877

\section{HAL Id: hal-02152877 \\ https://hal.science/hal-02152877}

Submitted on 20 Apr 2020

HAL is a multi-disciplinary open access archive for the deposit and dissemination of scientific research documents, whether they are published or not. The documents may come from teaching and research institutions in France or abroad, or from public or private research centers.
L'archive ouverte pluridisciplinaire HAL, est destinée au dépôt et à la diffusion de documents scientifiques de niveau recherche, publiés ou non, émanant des établissements d'enseignement et de recherche français ou étrangers, des laboratoires publics ou privés. 


\title{
Thermal modeling and optimization of microalgal biomass production in the harsh desert conditions of State of Qatar
}

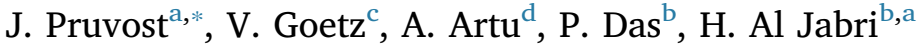 \\ ${ }^{a}$ GEPEA, Université de Nantes, CNRS, UMR6144, bd de l'Université, CRTT, BP 406, 44602 Saint-Nazaire Cedex, France \\ ${ }^{\mathrm{b}}$ Algal Technologies Program, Centre for Sustainable Development, College of Arts and Sciences, Qatar University, P.O. Box: 2713, Doha, Qatar \\ c PROMES-CNRS, UPR 8521, Tecnosud, Rambla de la Thermodynamique, 66100 Perpignan, France \\ d Algosource Technologies, Bd de l'Université, CRTT, BP 406, 44602 Saint-Nazaire Cedex, France
}

\section{A R T I C L E I N F O}

\section{Keywords:}

Microalgae

Solar cultivation

Modeling

Temperature

Heat transfers

Raceway

Desert

\begin{abstract}
A B S T R A C T
Microalgal culture in solar conditions raises several challenges, especially in the harsh desert areas of the Middle East where microalgal culture is a valuable candidate for biomass production on non-arable land.

Here we investigate issues related to the temperature regimes involved in open culture systems used to cultivate microalgae in the State of Qatar. A generic thermal modeling approach is presented. The model produced takes into account all relevant heat exchanges involved in the process, including solar radiation absorption, water evaporation and convection with ambient air, and is proved valid for accurate prediction of temperature regimes.

The model is then used to analyze heat exchanges and thermal behavior of the process for both summer and winter periods. Temperature regimes are then compared to the requirements of a heat-resistant and a temperateclimate microalgal strain. Finally, various simulations are run to identify how to set an optimized yearly microalgal culture in harsh desert conditions.
\end{abstract}

\section{Introduction}

Microalgal culture is developing fast, driven by increasing demand for large-scale production capacities for various applications such as food and feed industries. Whatever the technology (open or closed), optimal operation in real-world outdoor conditions poses a number of challenges, especially (i) culture contamination issues, (ii) optimization of light conversion by the culture to achieve maximal system performances, and (iii) maintaining optimal growth conditions such as temperature of culture [1-4].

The temperature and thermal regulation of microalgal culture systems is known as a major issue of solar microalgal cultivation [5-9]. Photosynthetic growth is strongly exoenergetic [10-13], with a thermodynamic efficiency over the photosynthetically active radiation (PAR) region below 5\% [14]. More than 95\% of the captured light is then converted into heat by biochemical reactions and dissipation in light-collecting antennae. Under outdoor conditions, heat generation is amplified by solar radiation in the infrared bandwidth (above $750 \mathrm{~nm}$, around $50 \%$ of solar energy) that directly participates in heating the culture $[6,8,9,11]$. Because of this heating, closed systems (photobioreactors) tend to overheat whereas open systems suffer water evaporation under strong incident irradiance.

In terms of biological requirements, the appropriate temperature window is strongly dependent on species cultivated but is typically in the $10-30{ }^{\circ} \mathrm{C}$ range. In practice, such temperatures are easily exceeded in summer, even in temperate climates, in which case the temperatures reached can become lethal to living microorganisms. This illustrates why culture cooling is usually a major engineering issue, especially when using closed photobioreactor geometries. Most microalgae species can tolerate low temperatures (below $10^{\circ} \mathrm{C}$ ), but this generally results in loss of biomass growth and productivity. Heating the culture can thus be beneficial in winter and in cold climates [8].

There are various solutions available for heating or cooling microalgal culture systems depending on their design, size, and location. Water cooling and/or heating by spraying the outside photobioreactor surfaces or by direct immersion in a pool are often used [5]. In temperate regions, cultivation systems can also be placed in greenhouses, which is a solution that can be used for either open [15] or closed culture systems [16].

Even though there are technical solutions, temperature control remains a challenge under solar conditions, especially when the project brief is for a cost-effective solution with low energy consumption (the

\footnotetext{
* Corresponding author.

E-mail address: jeremy.pruvost@univ-nantes.fr (J. Pruvost).
} 

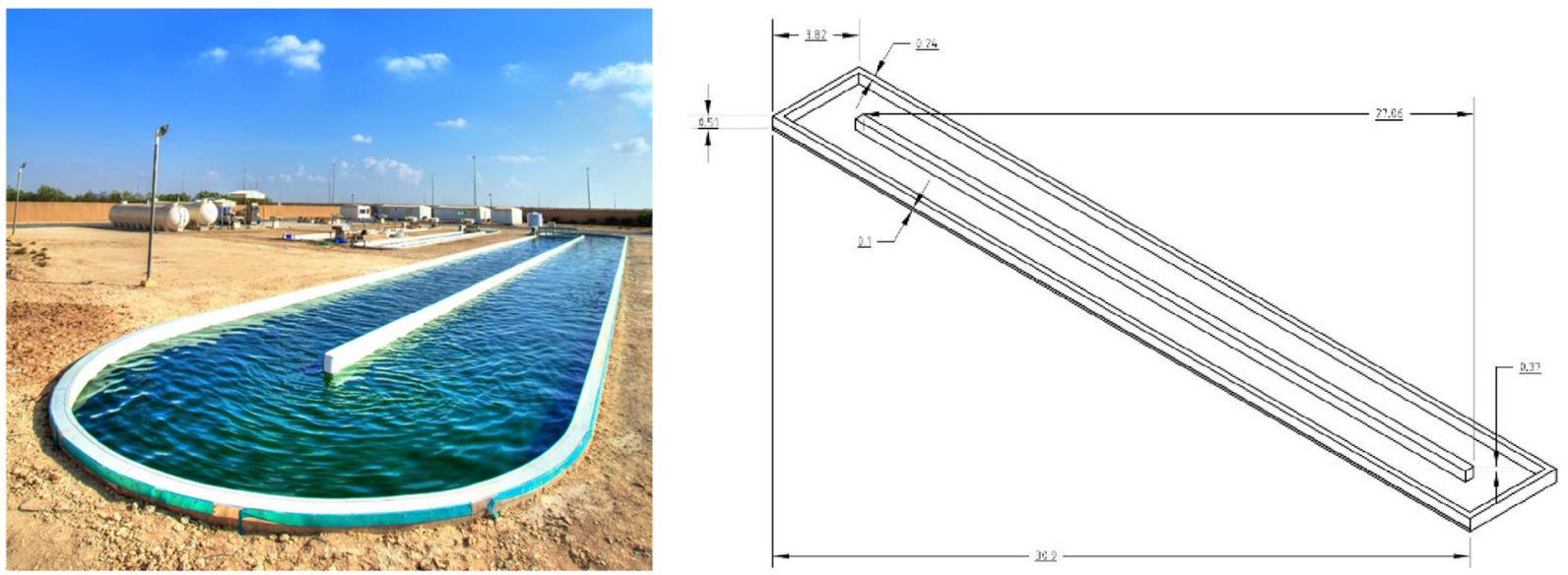

Fig. 1. The semi-buried raceway used for microalgal culture in Qatar.

cost related to thermal regulation can reach $50 \%$ of total operational cost). Year-round operation can also lead to the need for both cooling and heating. Cultivation-system engineering is also a factor, and optimal temperature regimes are dependent on the strain to be cultivated. For climates with large variations in outdoor temperature and solar irradiation over the course of a year, it could be beneficial to cultivate different species with optimal growths at different temperatures [8], which could significantly decrease energy needs over the period of operation.

Today there are several tools and models available for in-depth investigation into the effects of solar culture conditions, including outdoor research facilities, fully controlled lab-scale photobioreactors simulating outdoor conditions, and theoretical models [17-19]. Thermal modeling is a particularly valuable tool here, as is serves to simulate various technologies and designs [20-22]. Once validated, models can optimize design through simulations of culture system engineering and operation, and also open the possibility of setting advanced-control algorithms for optimal thermal regulation strategies.

Goetz et al. [6] investigated the effect of various flat-panel photobioreactor designs. Here we used thermal modeling applied on solar photobioreactors to accurately predict temperature regimes in the culture system. This enabled us to use the model to determine the monthly evolution of energy consumption required to maintain culture temperature in the range of microalgae requirements. Infrared filtering and other strategies for reducing culture overheat were then simulated.

Slegers et al. [20] modeled temperature regimes in open culture systems and demonstrated the strong influence of climate conditions on resulting culture temperature regimes. Strong variations were obtained, with temperature often below and above the optimal operating range, prompting the authors to conclude on the relevance of choosing a microalgal strain to fit the obtained temperature regimes. Temperature regime found for a summer day in Algeria, for example, was between $17^{\circ} \mathrm{C}$ and $28^{\circ} \mathrm{C}$. A possible solution was to adjust pond depth to modify the thermal inertia of the culture system and, thus, the resulting temperature regime. Increasing culture depth from $0.1 \mathrm{~m}$ to $0.5 \mathrm{~m}$ narrowed the range of temperature variations over a day of operation by around $5{ }^{\circ} \mathrm{C}$, but it also directly affected the volumetric biomass productivity of the culture system, making it necessary to find a compromise.

Overall, thermal regulation of any cultivation system depends on location, time of year, and strain cultivated. In desert environments, such as those found in the Middle East (State of Qatar), microalgae provides an alternative sustainable solution for food security, especially with the lack of sufficient arable land and fresh water for conventional agriculture. Some desert environments feature seemingly beneficial conditions for algae cultivation, such as ample sunlight, and high temperatures. However, the extremity of these conditions could have negative effect on algae growth rate and metabolites. Especially the concern of temperature issue (average ambient temperature around $40^{\circ} \mathrm{C}$ in summer). In that context, Qatar University has screened local species to isolate temperature-resistant strains [23]. Various culture systems were also tested. Potentially important strains were grown in open raceway ponds [24], and 301 size thin-film commercial photobioreactors (unpublished data); the energy requirement to cool the photobioreactors were found extremely high.

Here we present a thermal model of a semi-buried raceway system used to cultivate microalgae in the Qatar desert. After experimental validation on a real-world system operated in Qatar, the model is used to predict temperature time-courses encountered in summer and winter periods. A detailed analysis of heat exchanges involved in the process is then given. Temperature regimes are then compared to the requirements of two typical microalgal species, i.e. a heat-resistant strain and a temperate-climate strain. Finally, various simulations are run to investigate the value of introducing thermal regulation means, and recommendations are given on how to set an optimized year-round microalgal culture system in harsh desert conditions.

\section{Theoretical considerations}

\subsection{Experimental set-up}

The raceway (Fig. 1) pond was operated at Zubrah, in the north of Qatar. The details of the raceway pond $(35 \mathrm{~m} * 3.5 \mathrm{~m})$ is given elsewhere [24]; culture $\mathrm{pH}$ and temperature were recorded using multiparameter probe (YSI company, USA).

\subsection{Thermal modeling}

As the culture system is particularly shallow compared to its length and width, the thermal model was established assuming a mono-dimensional system (Fig. 2). As a semi-buried system, this was necessary to accurately represent thermal exchanges between culture volume and the ground. The system was then modeled as four distinct sub-systems: a first sub-system formed by the solution (culture volume), a second sub-system formed by the liner, a third sub-system formed by the concrete slab of the raceway, and a fourth sub-system formed by the ground (sand). Because of the permanent paddlewheel mixing, there is no temperature gradient in the culture volume. The culture medium is at a uniform temperature. Because of a very low thickness of the liner $(1 \mathrm{~mm})$, this sub-system is not discretized. In contrast, the concrete basis and the ground were discretized in connected elements (ten and a hundred elements, respectively) for an accurate representation of the heat transfer operating by conduction. Heat balances to describe the thermal behavior of the raceway were carried out from the nodal 


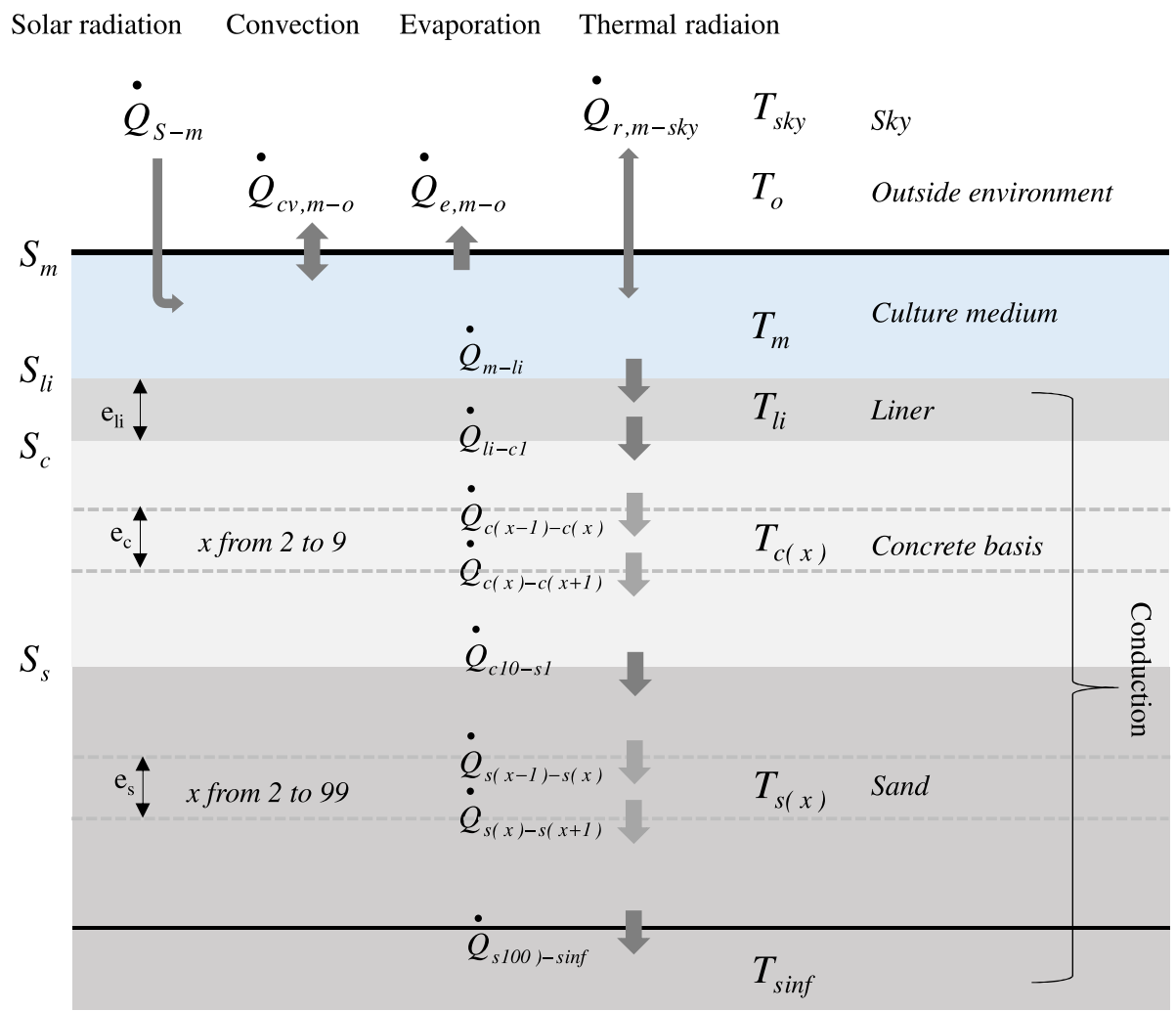

Fig. 2. Heat exchanges used in the thermal model.

network defined by the different subsystems (Fig. 2).

They were obtained by considering heat transfers generated by the absorption of solar radiation $\left(\dot{Q}_{S, m}\right)$; radiation between the culture and the sky $\left(\dot{Q}_{r, m-s k y}\right)$; culture medium evaporation $\left(\dot{Q}_{e, m-o}\right)$; convection between the solution surface and the surrounding $\left(\dot{Q}_{c v, m-o}\right)$; heat exchange between the solution and the liner $\left(\dot{Q}_{m-l i}\right)$; conduction in the bottom structures (concrete slab and sand ground, $\dot{Q}_{c}$ and $\dot{Q}_{s}$ respectively).

For the culture volume (subscript $\mathrm{m}$ ), this gives the following equation (mass $(\mathrm{m})$ and heat capacity $\left(\mathrm{C}_{\mathrm{p}}\right)$ of all materials are given in Table 1):

$m_{m} \cdot C p_{m} \frac{d T_{m}}{d t}=\dot{Q}_{S, m}-\dot{Q}_{c v, m-o}-\dot{Q}_{m-l i}-\dot{Q}_{r, m-s k y}-\dot{Q}_{e, m-o}$

where $T_{m}$ is temperature of the culture medium.

Most of the heat fluxes were obtained by applying standard heat transfer equations:

- for convection between the solution surface and the surroundings, with $T_{o}$ the outside ambient temperature, $S_{m}$ the culture surface area, and $h_{m-o}$ the convection heat exchange coefficient between the culture medium and the surrounding:

$\dot{Q}_{c v, m-o}=h_{m-o} S_{m}\left(T_{m}-T_{o}\right)$
- for convection between the solution and the liner, with $h_{m-l i}$ and $\lambda_{l i}$ the convection heat exchange coefficient between the culture medium and the liner, $S_{l i}$ the liner surface area and $\lambda_{l i}$ the thermal conductivity of the liner:

$\dot{Q}_{m-l i}=\left[\frac{1}{h_{m-l i} S_{l i}}+\frac{e_{l i} / 2}{\lambda_{l i} S_{l i}}\right]^{-1}\left(T_{m}-T_{l i}\right)$

with $e_{l i}$ the thickness of the liner $(1 \mathrm{~mm})$.

- for radiation between the culture and the sky (assuming the sky as a black body; $\varepsilon_{s k y}=1$ ):

$\dot{Q}_{r, m-s k y}=\sigma \varepsilon_{m} S_{m}\left(T_{m}^{4}-T_{s k y}^{4}\right)$

with $\sigma$ the Boltzamnn constant and $\varepsilon_{m}$ emissivity of the culture medium (Table 1).

In Eq. (4), radiations due to atmospheric emission was expressed by an equivalent sky temperature $T_{\text {sky }}[30]$ :

$T_{\text {sky }}=0.0552 \cdot T_{o}^{1.5}$

As for any open systems, thermal exchange due to water evaporation has to be taken into account. This is especially the case in a hot dry climate as in Qatar State where evaporation rates are high. Das et al. [24] found that evaporation water loss could be of $0.74-0.80 \mathrm{~cm} /$ day

Table 1

Constants and data used in the thermal balance equations.

\begin{tabular}{|c|c|c|c|c|c|c|c|c|c|}
\hline \multirow[t]{2}{*}{ Component } & $m$ & V & $e$ & $\rho$ & $C p$ & $S$ & $\lambda$ & $\alpha$ & $\varepsilon$ \\
\hline & $(\mathrm{kg})$ & $\left(\mathrm{m}^{3}\right)$ & $(\mathrm{m})$ & $\left(\mathrm{kg} \cdot \mathrm{m}^{-3}\right)$ & $\left(\mathrm{J} \cdot \mathrm{kg}^{-1} \cdot \mathrm{K}^{-1}\right)$ & $\left(\mathrm{m}^{2}\right)$ & $\left(\mathrm{W} \cdot \mathrm{m}^{-1} \cdot \mathrm{K}^{-1}\right)$ & $(-)$ & $(-)$ \\
\hline Culture medium & 9160 & 9.16 & 0.1 & 1000 & 4180 & 91 & 0.6 & 0.9 & 1 \\
\hline Concrete basis & 2600 & 1.18 & 0.1 & 2200 & 880 & 118 & 1.5 & - & - \\
\hline Ground (sand) & Infinite & Infinite & 5 & 1600 & 835 & 118 & 0.33 & - & - \\
\hline Liner & 82 & 0.09 & 0.001 & 900 & 2300 & 91 & 0.4 & - & - \\
\hline
\end{tabular}


could be achieved in the raceway culture system simulated here. Water evaporation obviously also applies to many other cases such as swimming pools, lakes, irrigation plants, or solar stills. It is mainly related to two processes: forced evaporation due to air flow across the liquid surface and the free evaporation due to moisture difference between ambient air and air above the medium surface. Sartori [25] introduces a general relation to represent thermal exchange due to water evaporation:

$\dot{Q}_{e, m-o}=S_{m}\left(A+B v_{w}\right) *\left(P_{s a t, \mathrm{~m}}-R H \cdot P_{s a t, o}\right)^{n}$

where $\mathrm{V}_{\mathrm{w}}$ is wind speed $(\mathrm{m} / \mathrm{s}), \mathrm{P}_{\mathrm{sat}}$ is saturated vapor pressure $(\mathrm{Pa})$ and $\mathrm{RH}$ is relative humidity of the ambient air.

A, B and n of Eq. (6) are semi-empirical coefficients. Different values are found in the literature. A comparison conducted by Tang and Etzion [26] found that even if most of the equations were close to reality, the following one was more accurate, so we used that equation here:

$\dot{Q}_{e, m-o}=S_{m}\left(0.2253+0.2464 \cdot v_{w}\right) \cdot\left(P_{s a t, m}-R H \cdot P_{s a t, o}\right)^{0.82}$

where $\mathrm{P}_{\text {sat }}(\mathrm{Pa})$ is given by Tang and Etzion [26]:

$P_{\text {sat }}=3385.5 e^{-8.0929+0.97608(T+42.607)^{0.5}}$

with $\mathrm{T}$ the outside temperature $\left(T_{o}\right)$ or temperature of the medium $\left(T_{m}\right)$.

Heat flux due to absorption of solar radiation was obtained from the global solar radiation $(\mathrm{q})$ at the culture surface $\left(\mathrm{S}_{\mathrm{m}}\right)$. As discussed in Goetz et al. [6], the radiation behavior of a microalgal culture volume is close to a black body. Microalgal culture systems generally reach full light absorption, and most of the irradiation spectrum is then absorbed by cell pigments or by the water itself (a depth of a few millimeters is enough for full absorption of infrared wavelengths). The visible part, which is absorbed by cells for photosynthetic conversion, convers into around $95-98 \%$ heat (the counterpart of the thermodynamic efficiency of photosynthetic conversion, which is around $2-5 \%$, [14]). This assumption obviously greatly simplifies the determination of heat flux absorbed by the system. It can be simply obtained from the irradiation collected by culture system and by introducing an absorptivity coefficient $\alpha_{\mathrm{m}} \approx 1$ to represent the light flux $q$ converted as heat:

$\dot{Q}_{S, m}=\alpha_{m} \mathrm{q} S_{m}$

The convection heat exchange coefficient between the culture medium and the outside environment $\left(h_{m-o}\right)$ was approached by an empirical correlation [27]. This relation was already applied and validated in Goetz et al. [6]:

$h_{m-o}=5.7+3.8 v_{w}$

As a result, $h_{m-o}$ was related to wind speed leading to $h_{m-o}$ values in the range of $10-40 \mathrm{~W} / \mathrm{m}^{2} \cdot \mathrm{K}$. The convection heat exchange coefficient between the culture medium and the liner $\left(h_{m, l i}\right)$ was determined considering a turbulent flow for the culture medium $\left(h_{m, l i}=360 \mathrm{~W} /\right.$ $\left.\mathrm{m}^{2} \cdot \mathrm{K}\right)$.

The same procedure was applied for the bottom structure (liner, concrete slab and sand ground), which was discretized as shown in Fig. 2.

For the liner (subscript li), this gives the following equation:

$m_{l i} \cdot C p_{l i} \frac{d T_{l i}}{d t}=-\dot{Q}_{m-l i}-\dot{Q}_{l i-c 1}$

with $\dot{Q}_{l i-c 1}=\left[\frac{e_{l i} / 2}{\lambda_{l i} S_{l i}}+\frac{{ }^{e} c / 2}{\lambda_{c} S_{c}}\right]^{-1}\left(T_{l i}-T_{c 1}\right)$, with $e_{c}$ the tenth of thickness of the concrete $\left(e_{c}=5 \mathrm{~mm}\right.$, total thickness of $\left.50 \mathrm{~mm}\right), \lambda_{l i}$ and $\lambda_{c}$ thermal conductivity of liner and concrete basis respectively, and $S_{l i}$ and $S_{c}$ surface area of liner and concrete basis respectively.

For the concrete basis (subscript c), the discretization leads to write:

- for the first layer $\mathrm{c} 1$ : $m_{c 1} \cdot C p_{c 1} \frac{d T_{c 1}}{d t}=-\dot{Q}_{l i-c 1}-\dot{Q}_{c 1-c 2}$

with $\dot{Q}_{c 1-c 2}=\frac{\lambda_{c} S_{c}}{e_{c}}\left(T_{c 1}-T_{c 2}\right)$

- for any intermediate layer from c2 to $\mathrm{c} 9$ (thickness $\mathrm{e}_{\mathrm{S}}$ ):

$m_{c(x)} \cdot C p_{c(x)} \frac{d T_{\mathcal{c}(x)}}{d t}=-\dot{Q}_{c(x)-c(x-1)}-\dot{Q}_{c(x)-c(x+1)}$

with $\dot{Q}_{c(x)-c(x+1)}=\frac{\lambda_{c} S_{c}}{e_{c}}\left(T_{c(x)}-T_{c(x+1)}\right)$

- for the final layer c10:

$m_{c 10} \cdot C p_{c 10} \frac{d T_{c 10}}{d t}=-\dot{Q}_{c 9-c 10}-\dot{Q}_{c 10-s 1}$

with $\dot{Q}_{c 10-s 1}=\left[\frac{e_{c} / 2}{\lambda_{c} S_{c}}+\frac{e_{s} / 2}{\lambda_{s} S_{s}}\right]^{-1}\left(T_{c 10}-T_{s 1}\right)$ with $e_{s}$ the hundredth of thickness of the sand $\left(e_{s}=50 \mathrm{~mm}\right.$, total thickness of $5 \mathrm{~m}$ ), and $\lambda_{s}$ and $S_{c}$ sand ground thermal conductivity and surface area respectively.

Finally, for the sand (subscript s), the discretization leads to write:

- for the first layer s1:

$m_{s 1} \cdot C p_{s 1} \frac{d T_{s 1}}{d t}=-\dot{Q}_{c 10-s 1}-\dot{Q}_{s 1-s 2}$

with $\dot{Q}_{s 1-s 2}=\frac{\lambda_{s} S_{s}}{e_{s}}\left(T_{s 1}-T_{s 2}\right)$.

- for any intermediate layer from s2 to s99 (thickness $\mathrm{e}_{\mathrm{s}}$ ):

$m_{s(x)} \cdot C p_{s(x)} \frac{d T_{S(x)} S_{s}}{d t}=-\dot{Q}_{s(x)-s(x-1)}-\dot{Q}_{s(x)-s(x+1)}$

with $\dot{Q}_{s(x)-s(x+1)}=\frac{\lambda_{s} S_{S}}{e_{S}}\left(T_{s(x)}-T_{s(x+1)}\right)$

- for the final layer s100:

$m_{s 100} \cdot C p_{s 100} \frac{d T_{s 100}}{d t}=-\dot{Q}_{s 99-s 100}-\dot{Q}_{s 100-\sin f}$

with $\dot{Q}_{s 100-\operatorname{sinf}}=\frac{\lambda_{S} S_{S}}{e_{S}}\left(T_{s 100}-T_{\text {sinf }}\right)$ and $T_{\text {sinf }}=28^{\circ} \mathrm{C}$

Meteorological input data (solar radiation, wind speed, ambient temperature, air humidity) were recorded during experiments (model validation section), or sourced from the meteorological database (simulation section). Note that $q$ is total radiation, i.e. the sum of direct and diffuse solar radiation.

\subsection{Characteristics of the strains}

It is well-known that microalgae species exhibit various temperature requirements. Qatar University isolated recently several species from the Qatar desert [23] that were found to have acclimated to the hot climate, conferring them greater resistance to high temperature than species usually found in temperate climates. To relate the thermal behavior of the culture system with microalgal growth requirements, we considered two typical strains: a "hot-climate strain" representative of a desert-isolated strain, and a "temperate-climate strain" presenting temperature requirements usually encountered in climates like Europe.

For both strains, a critical range and a targeted operating range were defined. Most species can tolerate some variation near their optimal growth temperature with only moderate effect on their growth kinetics [20]. This factor was used to define the targeted operating range. However, if the temperature is too low or too high, it can have strong or even lethal biological effects and so should obviously be avoided in practice. This factor was thus used to define the critical regime. Corresponding values are given in Table 2 . Note that these requirements were defined semi-empirically, in accordance with our aim to illustrate issues related to the thermal behavior of culture systems in harsh desert conditions. Precise determination of strain requirements would require further characterization, for instance using lab-scale photobioreactors 
Table 2

Temperature requirements of the "hot-climate" strain and "temperate-climate" strain. Targeted operating range is the temperature range that may trigger optimal growth, whereas critical range is the temperature range that may trigger strong adverse biological effects.

\begin{tabular}{lcl}
\hline & Targeted operating range & Critical regime \\
\hline Hot climate species & $28^{\circ} \mathrm{C}<\mathrm{T}<40^{\circ} \mathrm{C}$ & $\mathrm{T}<15^{\circ} \mathrm{C}$ or $\mathrm{T}>42^{\circ} \mathrm{C}$ \\
Temperate climate species & $20^{\circ} \mathrm{C}<\mathrm{T}<28^{\circ} \mathrm{C}$ & $\mathrm{T}<10^{\circ} \mathrm{C}$ or T $>30^{\circ} \mathrm{C}$ \\
\hline
\end{tabular}

to simulate various temperature regimes and to precisely determine the resulting effects on growth kinetics. For the sake of clarity, it was also assumed that optimal temperatures was identical during day and during night period, although decreasing the temperature of the algal culture during night may reduce the respiration activity [28]. Please note that the model could be easily adjusted to investigate such an effect.

\section{Results and discussion}

\subsection{Thermal model validation}

Fig. 3-a shows the ambient temperature and the solar radiation profiles recorded for a typical outdoor culture system in Qatar (data recorded in May 2016). Ambient temperature was between 25 and $37^{\circ} \mathrm{C}$, with photons flux density (PFD) higher than $1000 \mathrm{~W} \cdot \mathrm{m}^{-2}$ (i.e. PFD higher than $2000 \mu \mathrm{mole}_{\mathrm{h} \nu} \cdot \mathrm{m}^{-2} \cdot \mathrm{s}^{-1}$ in the PAR region). Temperature in the culture system was found to range between $22^{\circ} \mathrm{C}$ and $34^{\circ} \mathrm{C}$ (Fig. 3-b).

Fig. 3-b presents the temperature evolution predicted by the thermal model. Some model input data like relative humidity and windspeed were not obtained on-site but deduced from meteorological data measured at a nearby location (Doha city; see next section). To assess sensitivity of prediction to these input parameters, a deviation of $\pm 40 \%$ was considered on both relative humidity and windspeed. Fig. 3-b charts the corresponding temperature evolutions in dashed lines.

The simulated temperature profiles were in reasonable agreement with experimental profiles. Considering the simplifying assumptions and the uncertainty on some of the input data, the model described the dynamic thermal behavior of reactor fairly well, with an average prediction error on culture medium temperature of $1.5^{\circ} \mathrm{C}$ (maximum deviation of $4^{\circ} \mathrm{C}$ ). Maximum temperature reached in the culture system was correctly estimated, as was the transient regime induced by diurnal cycles.

\subsection{Temperature profiles during winter and summer operation}

Two typical averaged days were generated to investigate issues related to the thermal behavior of the culture system over a year of operation. Meteonorm software (www.meteonorm.com) was used to obtain the hour-by-hour evolution of meteorological data for Doha $\left(25.2^{\circ} \mathrm{N}\right.$ and $\left.51.3^{\circ} \mathrm{E}\right)$. Averaged days were then generated for summer and winter periods, corresponding to a month-long averaging of hourly data for July and January, respectively. The corresponding data for irradiation, ambient temperature, windspeed and ambient air relative humidity are given in Fig. 4.

Rather different outdoor conditions were obtained for the two seasons. The summer day reached an averaged ambient temperature of $36^{\circ} \mathrm{C}$ (against $18{ }^{\circ} \mathrm{C}$ in winter), with a relative humidity of $40 \%(68 \%$ in winter) and a windspeed of $4.2 \mathrm{~m} \cdot \mathrm{s}^{-1}\left(4 \mathrm{~m} \cdot \mathrm{s}^{-1}\right.$ in winter). Solar radiation showed a more moderate difference, with an averaged PFD of $480 \mu \mathrm{mol}_{\mathrm{h \nu}} \cdot \mathrm{m}^{-2} \cdot \mathrm{s}^{-1}$ in summer and $300 \mu \mathrm{mol}_{\mathrm{h \nu}} \cdot \mathrm{m}^{-2} \cdot \mathrm{s}^{-1}$ in winter, corresponding to total radiation values of $244 \mathrm{~W} \cdot \mathrm{m}^{-2}$ and $150 \mathrm{~W} \cdot \mathrm{m}^{-2}$, respectively (full-spectrum sunlight). Peak sunlight intensity values were also found high for both seasons, at $1490 \mu \mathrm{mol}_{\mathrm{h \nu}} \cdot \mathrm{m}^{-2} \cdot \mathrm{s}^{-1}$ (i.e. $750 \mathrm{~W} \cdot \mathrm{m}^{-2}$ ) in summer and $1110 \mu \mathrm{mol}_{\mathrm{h} \nu} \cdot \mathrm{m}^{-2} \cdot \mathrm{s}^{-1}$ (i.e. $560 \mathrm{~W} \cdot \mathrm{m}^{-2}$ ) in winter.

Fig. 5-a shows predicted temperature evolutions in the culture system for both summer and winter periods. In summer, the temperature evolution ranged between $24^{\circ} \mathrm{C}$ and $31^{\circ} \mathrm{C}$, which was around $7-8{ }^{\circ} \mathrm{C}$ below ambient temperature. In winter, culture temperature was found to stay very close to ambient temperature evolution, and ranged between $14^{\circ} \mathrm{C}$ and $21^{\circ} \mathrm{C}$. In both cases, the dynamics of change were found to be directly related to the radiation and ambient temperature profiles (both of which were also strongly inter-related).

One advantage of thermal modeling is that it offers the ability to calculate all thermal exchanges involved in the process. This is useful information for further engineering optimization (as done later in this work). Predicted thermal exchanges are represented in Fig. 5-b, which clearly shows the dynamics resulting from solar radiation absorption, with a peak value at noon. Note too that, during summer, energy input obtained through convective exchange was found similar to the energy input obtained through solar radiation (this will be confirmed later; see Fig. 8). This is explained by the high temperature of ambient air that remains hot during both day and night, resulting in an almost constant convective exchange over the $24 \mathrm{~h}$ period. This was associated with a significant loss of energy due to water evaporation, which peaked during the day due to the additional contribution of solar radiation. Considering the latent heat of water evaporation, this energy loss can be converted into a water loss, leading to a total loss of around 1-2 cm of water/day (around 10-201 per $\mathrm{m}^{2}$ of culture).

The significant contribution of water evaporation to the cooling of the culture temperature is a well-known feature of open culture

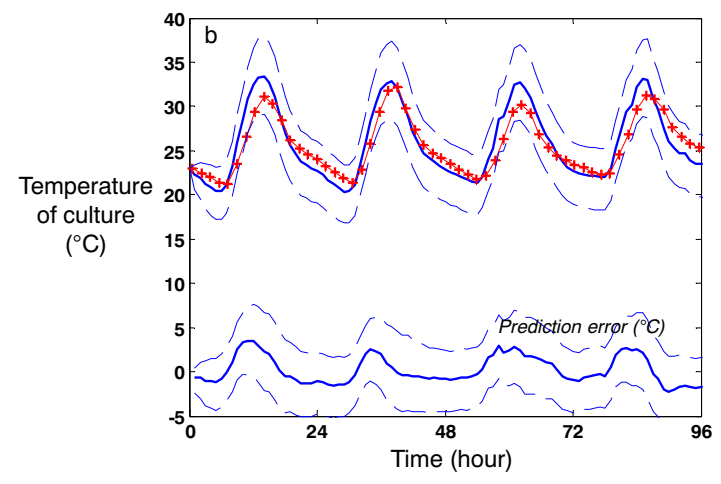

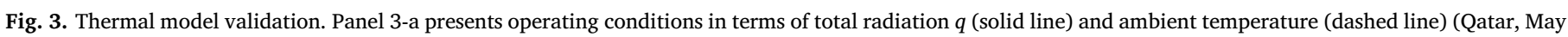

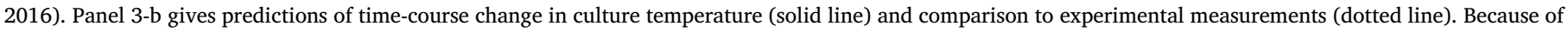
the uncertainty on input data, simulations were also run assuming a deviation of $\pm 40 \%$ on both relative humidity and windspeed (dashed lines). 

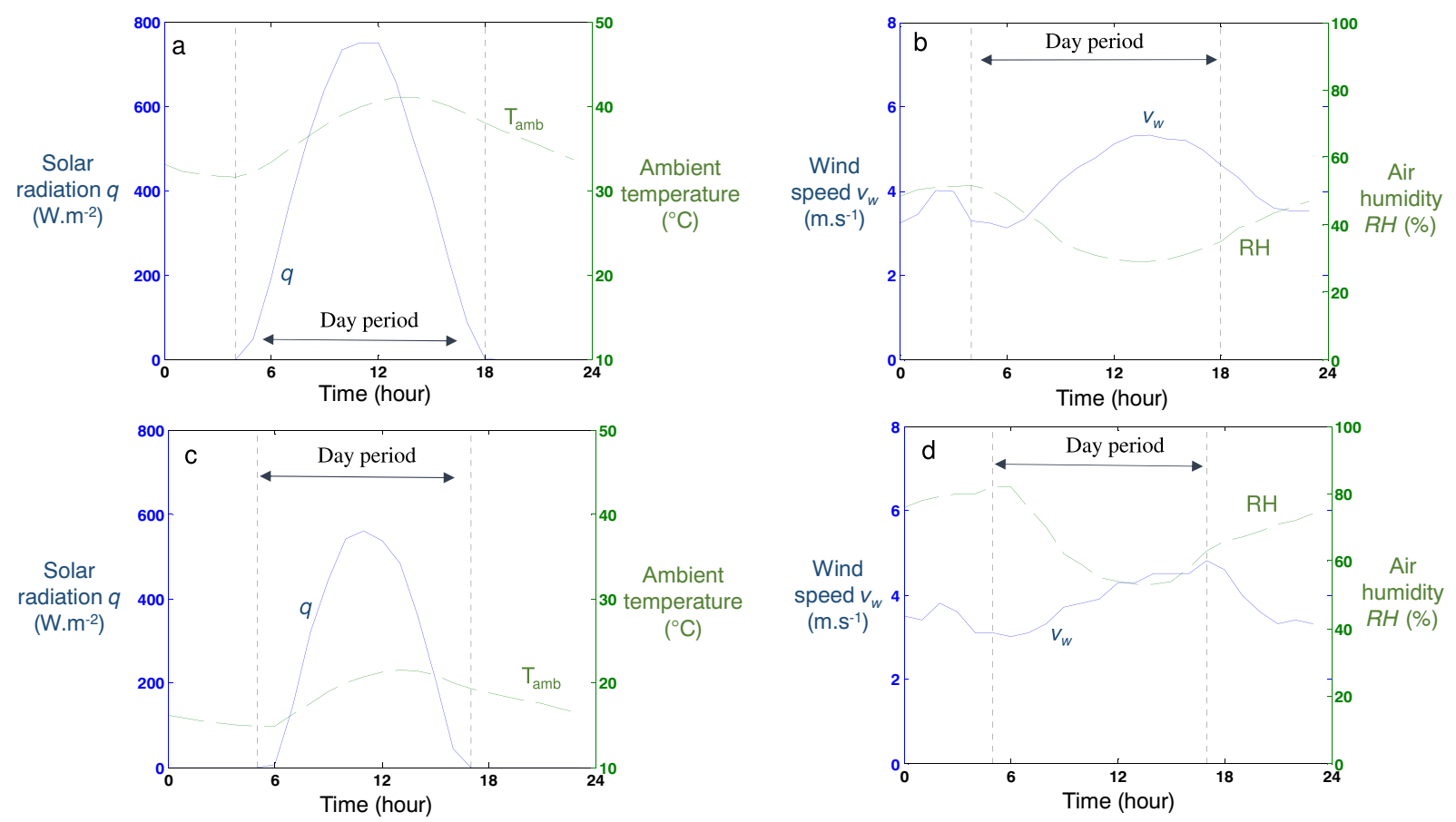

Fig. 4. Daily evolutions of meteorological conditions for summer (4-a\&b) and winter (4-c\&d) periods.

systems. Ali [29] showed that during the night, evaporation from a free water surface of $1 \mathrm{~m}^{2}$ with a water depth of $50 \mathrm{~cm}$ contributed from $38.7 \%$ to $57.4 \%$ of the total cooling power in a hot arid area (Egypt). This ratio may be even greater during the day and when water depth decreases (i.e. lower thermal inertia). The upshot is a significant loss of fresh water. Note that our predicted values are close to the experimentally-measured value reported in QU for the same system and location [24], which is evidence that our model can reliably predict the thermal and energy exchanges involved in open culture systems in these harsh desert conditions. Note too that with only slight modification, our model could be extended to predict time-course change in salinity, such as when using seawater with a resulting evaporation of (fresh) water. Although outside the scope of this study, this could be helpful for microalgae species sensitive to change in salinity.

For the winter period, although the energy input was also mainly due to solar radiation, convective exchange was very low. The fairly similar temperature levels mean that ambient air still provides thermal energy to the culture medium (positive values) but to a significantly
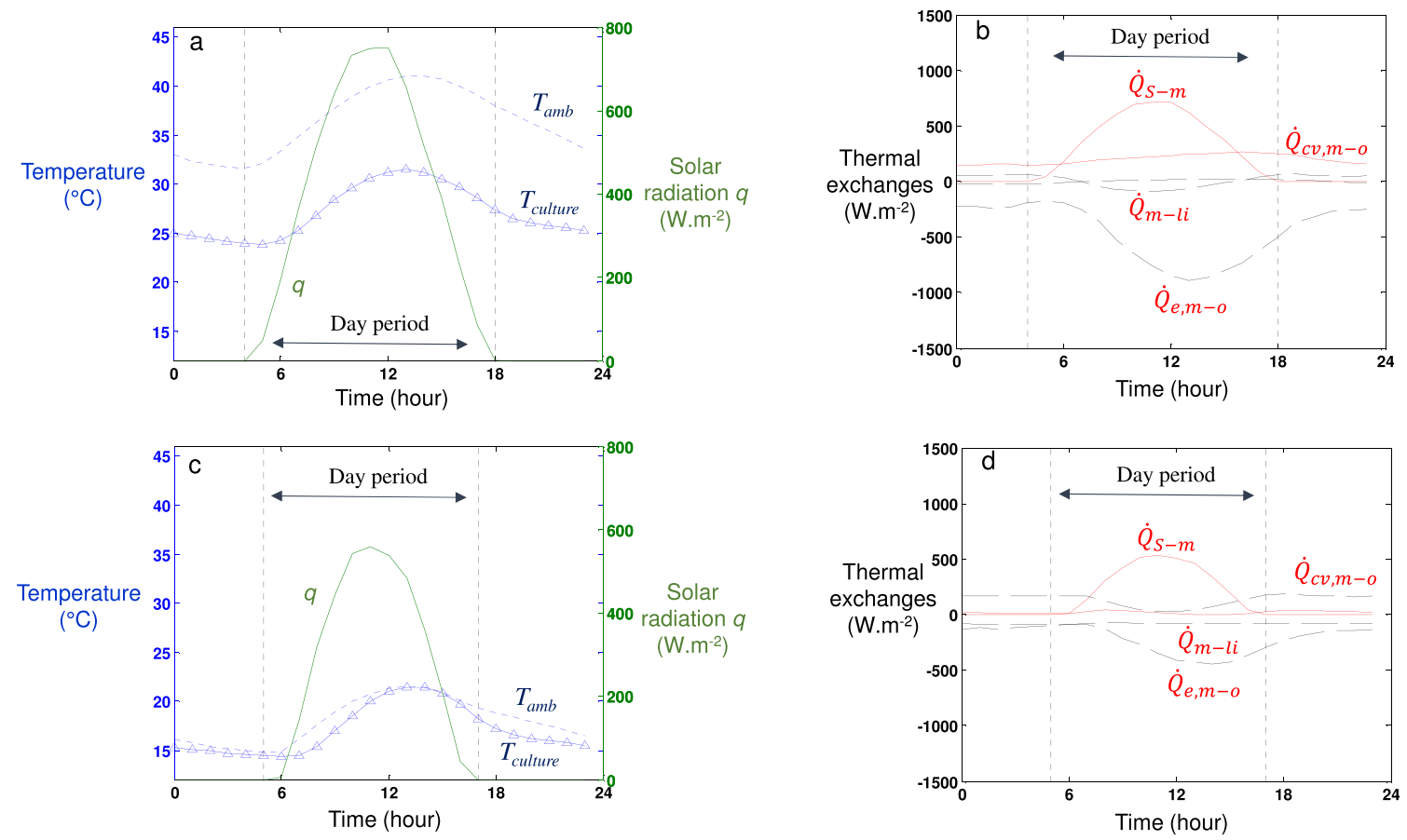

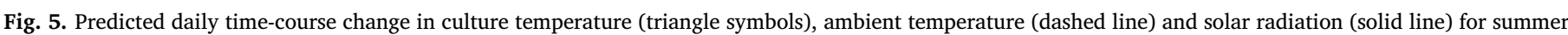

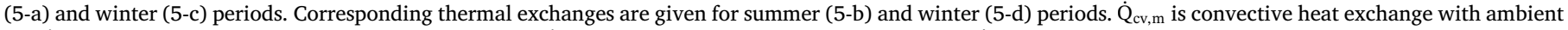
air, $\dot{\mathrm{Q}}_{\mathrm{cd}, \mathrm{m}}$ is conductive heat exchange with the ground, $\dot{\mathrm{Q}}_{\mathrm{s}, \mathrm{m}}$ is heat absorbed by solar radiation and $\dot{\mathrm{Q}}_{\mathrm{ev}}$ is energy loss through water evaporation. 


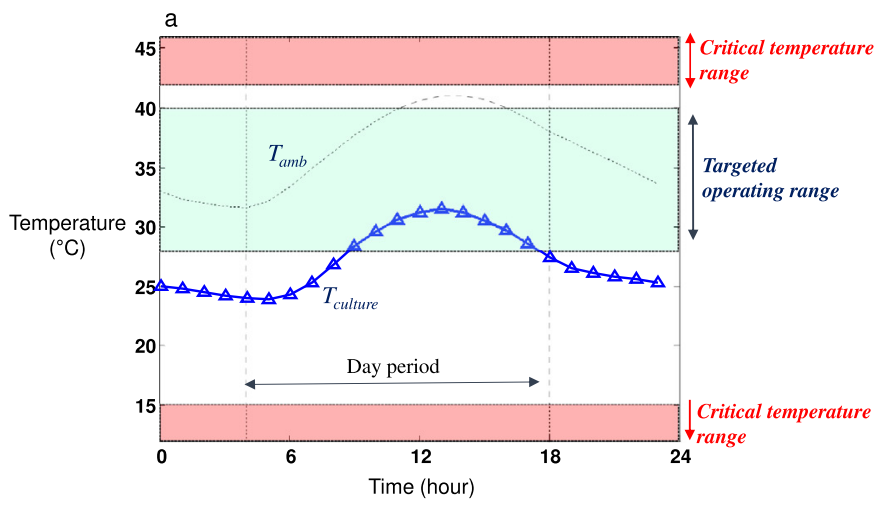

b

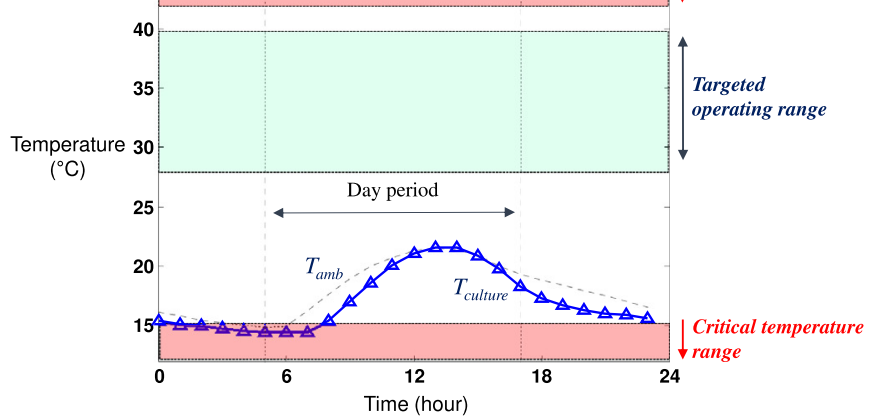

Fig. 6. Temperature requirements of the hot-climate strain compared against the temperature regimes obtained in raceways in summer (panel 6-a) and winter (panel 6-b).

lesser extent than in summer. Water loss due to evaporation is then greatly reduced (around $1 \mathrm{~cm} /$ day).

Finally, note that energy exchange with the ground was one order of magnitude larger in winter than in summer $\left(3.2\right.$ versus $0.3 \mathrm{kWh} \cdot \mathrm{m}^{-2}$ respectively; see under "Calculation of energy exchanged"). This is mainly explained by a larger differential between culture temperature and ground temperature (i.e. $28^{\circ} \mathrm{C}$ ) in winter $\left(14-21^{\circ} \mathrm{C}\right.$ ) than in summer $\left(24-31{ }^{\circ} \mathrm{C}\right)$, thus increasing the heat exchanges with the ground. Over a $24 \mathrm{~h}$ period, energy exchange by conduction was similar to the energy received from the sun during winter $\left(3.5 \mathrm{kWh} \cdot \mathrm{m}^{-2}\right)$ with a global warming effect (i.e. positive value). This points to a role of the ground on overall heat balance (this aspect will be further analyzed in the section devoted to the engineering optimization).

\subsection{Comparison with the strains temperature requirements}

The temperature requirements of the hot-climate strain (Qatar strain) were added to the temperature evolution profiles (Fig. 6). For the summer period (Fig. 6-a), the critical range was never reached. The culture was $9 \mathrm{~h}$ a day in the targeted operating range and $15 \mathrm{~h}$ with temperature below $28^{\circ} \mathrm{C}$ due to a drop in temperature at night. If we consider only the $13 \mathrm{~h}$ period of the day when photosynthesis occurs (from sunrise at 5 a.m. to sunset at 6 p.m.), the culture was in targeted operating range for around $70 \%$ of the day period. Only the first hours of the day from 5 to 9 a.m. were below the lower limit of the targeted operating range $\left(28^{\circ} \mathrm{C}\right)$. Note that ambient temperature also exceeds the upper limit of the targeted operating range $\left(40^{\circ} \mathrm{C}\right)$ during $4 \mathrm{~h}$. As discussed in the previous section, natural cooling due to water evaporation greatly reduced the culture temperature, leading in this case to temperature regimes that fit with hot-climate strain requirements.

Unlike in the summer period, culture temperature was never in the targeted operating range for the winter period (Fig. 6-b). Culture temperature was around $6-12{ }^{\circ} \mathrm{C}$ below the lower limit, and the critical temperature range $\left(<15^{\circ} \mathrm{C}\right)$ was obtained during $6-7 \mathrm{~h}$, from the end of the night to first hours of the day. These findings would suggest that the hot-climate strain could not be cultivated in winter without risk of culture loss (cell death) or at least with a significant loss of growth rate.
For solid confirmation, further experiments are needed to characterize the exact effect of these non-optimal temperature regimes, which could be done by applying temperature (and eventually light) regimes obtained from simulation in a lab-scale photobioreactor to quantify the exact effect on resulting productivity.

Based on previous results, it is acceptable at this stage to operate outside the targeted operating range (i.e. non-optimal temperature), to optimize the culture system engineering by introducing a means of thermal regulation for example (see next section), or to change cultivated species. To illustrate the value of changing cultivated species, we added the temperate-climate strain requirements to the temperature regimes (Fig. 7). This move was found more appropriate for winter culture. Although the targeted operating range was only maintained during $2 \mathrm{~h}$ around noon, the minimum temperature was only about $5{ }^{\circ} \mathrm{C}$ below the lower limit, and the critical regime was never reached. This could suggest only limited effect on resulting productivity. During summer, $15 \mathrm{~h}$ per day were in the targeted operating range, but unfortunately with only $3 \mathrm{~h}$ for the photosynthetically active period. Moreover, temperature was found to be too high during $9 \mathrm{~h}$ a day, including around $3 \mathrm{~h}$ in the critical regime. In fact, this critical regime was obtained at noon when higher irradiation values were obtained, which, combined with high temperature, is known to increase risk of photoinhibition, generating a high risk of culture loss.

The easy conclusion from these results is that combining appropriate strains raises prospects for full year-round operation with almost optimal growth conditions throughout the year. In our case, we would need a heat-resistant strain to enable culture in Qatar's extremely hot climate.

\subsection{Calculation of energy exchanged}

Values of energies Q expressed in $\mathrm{kWh} \cdot \mathrm{m}^{-2}$ exchanged during a day of operation and expressed per unit of the cultivated surface are given in Fig. 8, with and without means of thermal regulation (the case with thermal regulation will be discussed in the next section). Analysis of the contribution of each thermal exchange illustrates the thermal behavior of the culture system as a function of period in the year. 

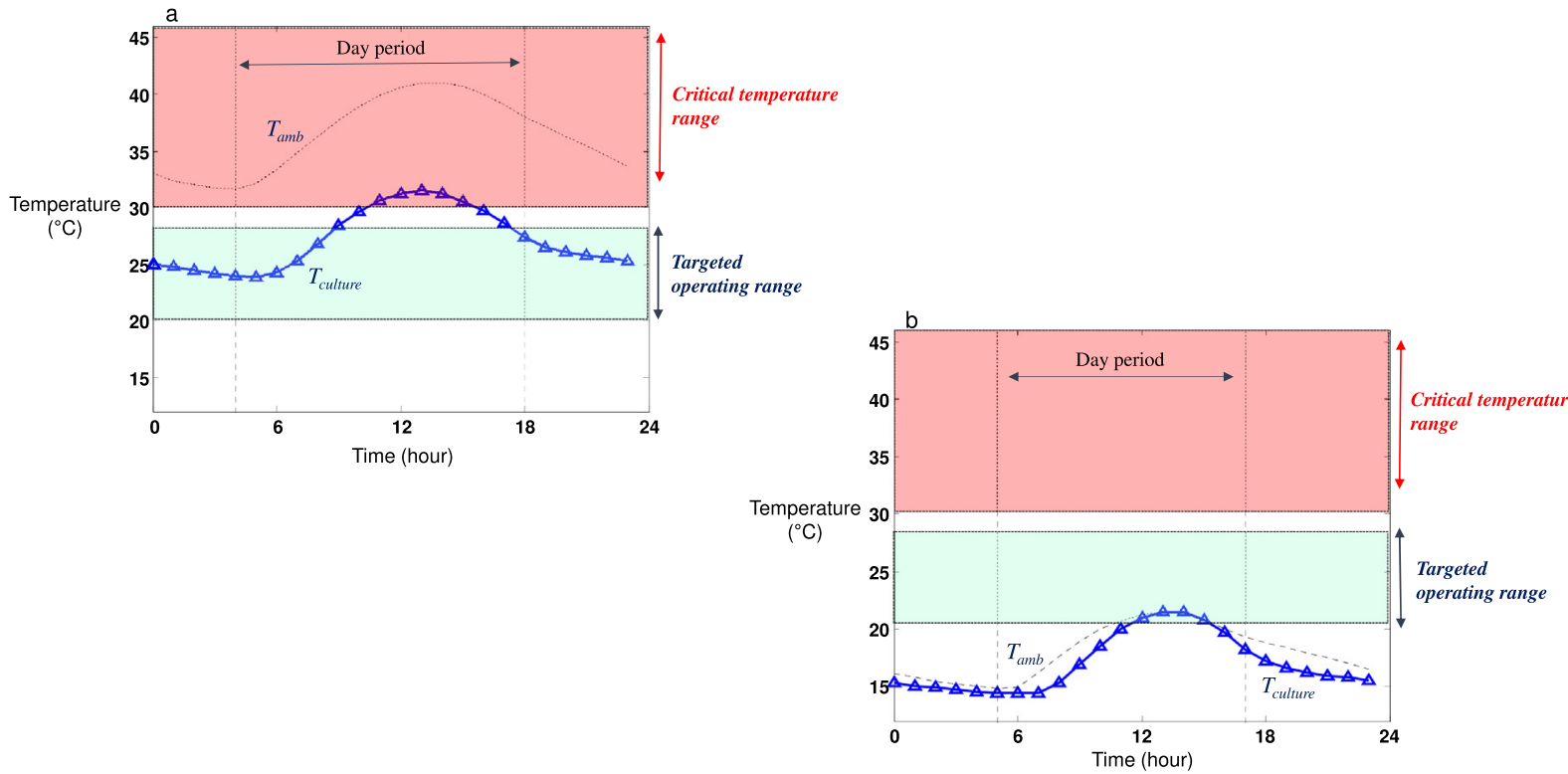

Fig. 7. Temperature requirements of the temperate-climate strain compared against the temperature regimes obtained in raceways in summer (panel 7-a) and winter (panel 7-b).

As already observed on the daily evolutions of heat exchanges (Fig. 5), in summer, without thermal regulation, the combined effect of wind and hot ambient temperature results in significant exchange at the medium surface, driving a strong contribution of evaporation (energy loss, $-10.7 \mathrm{kWh} \cdot \mathrm{m}^{-2}$ ) and convective heat exchange with ambient air (energy gain, $4.8 \mathrm{kWh} \cdot \mathrm{m}^{-2}$ ). These contributions were found in the range of solar radiation $\left(5.6 \mathrm{kWh} \cdot \mathrm{m}^{-2}\right.$, Fig. 8 -a\&c).

This pattern was not observed during winter. Without thermal regulation, solar radiation $\left(3.5 \mathrm{kWh} \cdot \mathrm{m}^{-2}\right)$ was found to be higher than convection $\left(0.4 \mathrm{kWh} \cdot \mathrm{m}^{-2}\right)$, but there was also a significant increase of heat exchange with the ground $\left(3.2 \mathrm{kWh} \cdot \mathrm{m}^{-2}\right)$ due to a more conducive ground temperature promoting exchanges with the culture, as already explained. Winter-season heat exchange due to evaporation decreased two-fold compared to summer due to the lower ambient temperature and higher relative humidity, which reduced evaporation rates $(1 \mathrm{~cm} /$ day in winter and $2 \mathrm{~cm} /$ day in summer). However, compared to other heat exchanges, evaporation still contributed substantially to all-round system cooling $\left(-5.2 \mathrm{kWh} \cdot \mathrm{m}^{-2}\right)$, bringing culture temperature down

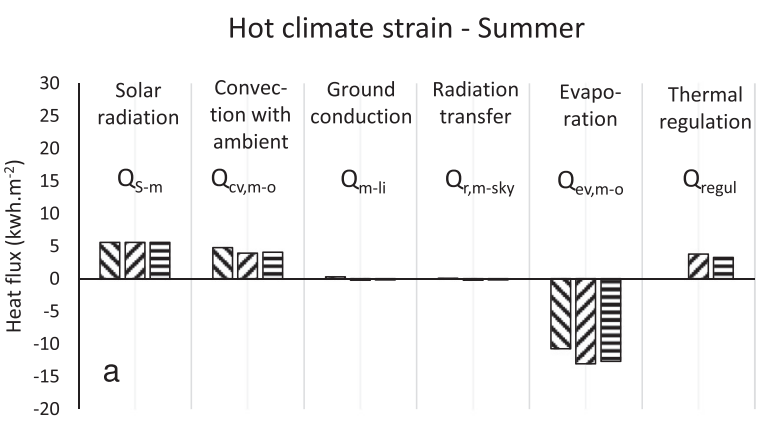

$\mathbf{N}$ No regulation $\boldsymbol{\square}$ Ideal thermal regulation unit (infinite power) $\boxminus$ Realistic regulation

Temperate climate strain - Summer

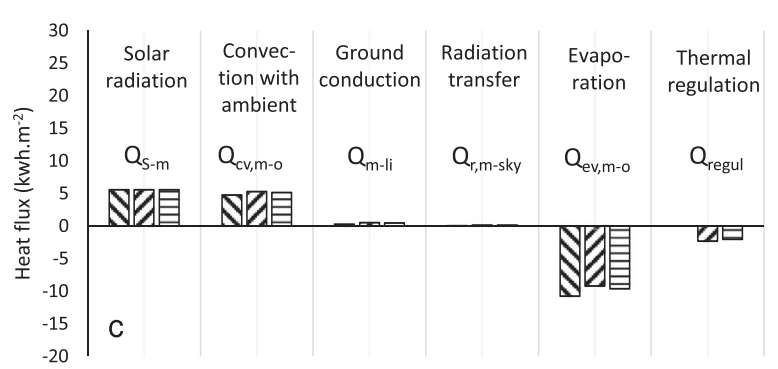

$\checkmark$ No regulation $\square$ Ideal thermal regulation unit (infinite power) $\boxminus$ Realistic regulation

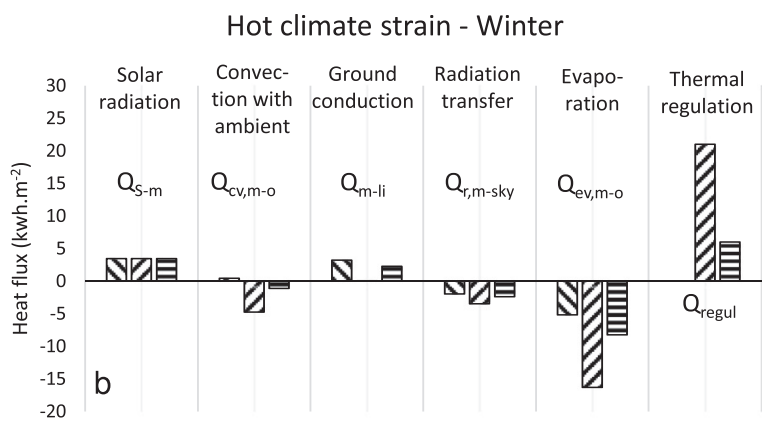

\No regulation $\mathbb{D}$ Ideal thermal regulation unit (infinite power) $\boxminus$ Realistic regulation

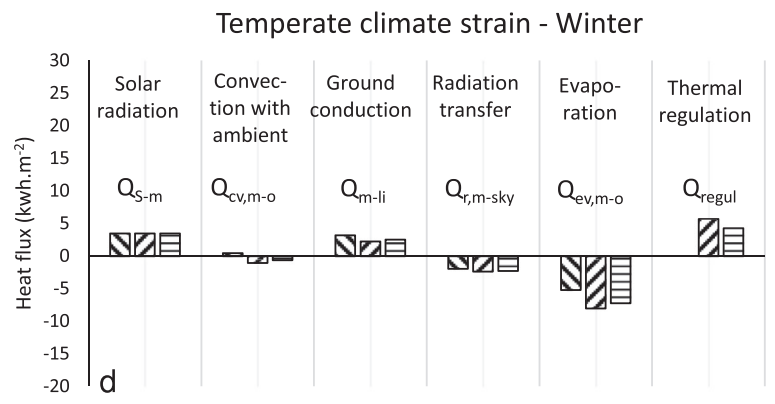

వNo regulation $\square$ Ideal thermal regulation unit (infinite power) $\boxminus$ Realistic regulation

Fig. 8. Values of heat energies exchanged over a day of exploitation for summer (panel 8-a\&c) and winter periods (panel 8-b\&d) and for the hot-climate (panel 8-a\&b) and temperate-climate (panel 8-c\&d) strains. Simulations were first conducted without any means of thermal regulation, and then with a thermal regulation unit aiming at maintaining the culture temperature requirements of each species. Optimal thermal regulation refers to the use of a thermal regulation unit of infinite power. Realistic thermal regulation refers to the use of a thermal regulation unit with a limited power of $250 \mathrm{~W}$ per unit of cultivated surface (see text for details). 
below strain requirements (Fig. 6).

\subsection{Value of thermal modeling for engineering optimization}

\subsubsection{Introducing thermal regulation means into the thermal model}

By means of external cooling or heating, it is possible to maintain the system in the targeted operating range. Basically, a heating-cooling system (i.e. temperature regulation unit) is activated as soon as the culture temperature is drifts out of the preset range. This can be simulated by adding a heat sink-source term $\dot{Q}_{\text {regul }}$ in the thermal balance of the culture:

$m_{m} \cdot C p_{m} \frac{d T_{m}}{d t}=\dot{Q}_{\text {regul }}+\sum \dot{\text { Heat fluxes }}$

This equation was applied during heating/cooling periods. The corresponding energy was then calculated by integrating the power obtained at all time-steps.

\subsubsection{Case of an ideal thermal regulation unit with infinite power}

We first assumed infinite power of the thermal regulation unit to estimate the energy needs for thermal regulation. This allowed to maintain culture temperature in the targeted operating range regardless of outside conditions, by calculating the instantaneous power to inject or extract in order to hold the temperature constantly inside the targeted range. An example of the corresponding temperature evolution is given in Fig. 9-a for the temperate-climate strain cultivated in summer.

Adding thermal regulation to keep culture temperature within the targeted range of each species was found to have direct effect on most thermal exchanges. In fact, all exchanges except heat absorbed from solar radiation were affected, as they are all directly related to culture temperature. For example, for the hot-climate species, a slight decrease in convective heat transfer (decrease from 4.8 to $3.9 \mathrm{kWh} \cdot \mathrm{m}^{-2}$ ) with ambient air was observed during summer (Fig. 8-a) as the operating range of culture temperatures $\left(28-40^{\circ} \mathrm{C}\right)$ was close to ambient temperatures $\left(32-42^{\circ} \mathrm{C}\right)$. However, during winter (Fig. 8-b), there was a significant loss of energy through convection (from $0.4 \mathrm{kWh} \cdot \mathrm{m}^{-2}$ to $-4.7 \mathrm{kWh} \cdot \mathrm{m}^{-2}$ ) due to the larger difference with ambient temperatures $\left(14-22^{\circ} \mathrm{C}\right)$. The higher culture temperature when thermal regulation is applied (minimum of $28^{\circ} \mathrm{C}$ instead of $14-22^{\circ} \mathrm{C}$ without thermal regulation; Fig. 6-b) means that evaporation rates also increased significantly $\left(-5.2 \mathrm{kWh} \cdot \mathrm{m}^{-2}\right.$ to $\left.-16.3 \mathrm{kWh} \cdot \mathrm{m}^{-2}\right)$. Ultimately this significantly increased energy loss over the whole culture system, which was then compensated by the large energy consumption for thermal regulation (around $21 \mathrm{kWh} \cdot \mathrm{m}^{-2}$, Fig. 8-b).

For the temperate-climate strain, the effect of thermal regulation on evaporation was reduced $\left(-9.2 \mathrm{kWh} \cdot \mathrm{m}^{-2}\right.$ instead of $\left.-10.7 \mathrm{kWh} \cdot \mathrm{m}^{-2}\right)$ due to the lower operating range of culture temperatures $\left(20-28^{\circ} \mathrm{C}\right)$. However, convective exchange was increased $\left(5.3 \mathrm{kWh} \cdot \mathrm{m}^{-2}\right.$ instead of $4.8 \mathrm{kWh} \cdot \mathrm{m}^{-2}$ ) due to a larger temperature differential with ambient air than in the case of the hot-climate species, In winter (Fig. 8-d), heat exchanges due to convection (from $0.4 \mathrm{kWh} \cdot \mathrm{m}^{-2}$ to $-1.1 \mathrm{kWh} \cdot \mathrm{m}^{-2}$ ) and evaporation loss (from $-5.2 \mathrm{kWh} \cdot \mathrm{m}^{-2}$ to $-8.1 \mathrm{kWh} \cdot \mathrm{m}^{-2}$ ) were both increased when thermal regulation was added, but to a lesser extent than when applying the hot-climate species temperature setpoints due to the lower culture temperatures and, therefore, lower temperatures differential with ambient air. As a result, less energy was necessary to maintain culture temperature of in the requisite operating range for the temperate-climate strain $\left(5.7 \mathrm{kWh} \cdot \mathrm{m}^{-2}\right.$ instead of $21 \mathrm{kWh} \cdot \mathrm{m}^{-2}$ in the winter period).

\subsubsection{Case of a realistic thermal regulation unit with limited power}

Regarding the large energy exchanged, and more precisely the large time-course variation in energies during a day of operation (Fig. 5), the hypothesis of a thermal regulation unit of infinite power (i.e. power sufficient large to consider an instantaneous and ideal thermal response of the system) can be considered unrealistic. To represent more realistic conditions, simulations were run to define real-world means of thermal regulation that could improve the thermal behavior of the culture system, but with realistic power values. This leads to introduce a limited power value $\dot{Q}_{\text {regul }}$ in Eq. (15). An example is given in Fig. 9-b for a power of $0.25 \mathrm{~kW} \cdot \mathrm{m}^{-2}$ (i.e. total power of around $23 \mathrm{~kW}$ for the entire cultivation system). Even though the thermal regulation unit decreased culture temperature when activated, its limited power proved ineffective at holding temperature within the targeted operating range, especially around the noon period. As a direct result, it resulted in a decrease in energy needs, especially for the hot-climate species in winter, from $21 \mathrm{~kW} \cdot \mathrm{m}^{-2}$ to $6 \mathrm{~kW} \cdot \mathrm{m}^{-2}$ (Fig. 8-b).

\subsubsection{Parametric study and investigation of various thermal regulation strategies}

Previous examples have highlighted the utility of thermal modeling to simulate various thermal regulation strategies. For a deeper analysis, the interested reader can refer to the Table given in Supplementary materials that reports results of a large set of simulated cases (as well as values obtained for previous simulations). Parameters like culture depth (which affects culture volume and thus the overall thermal

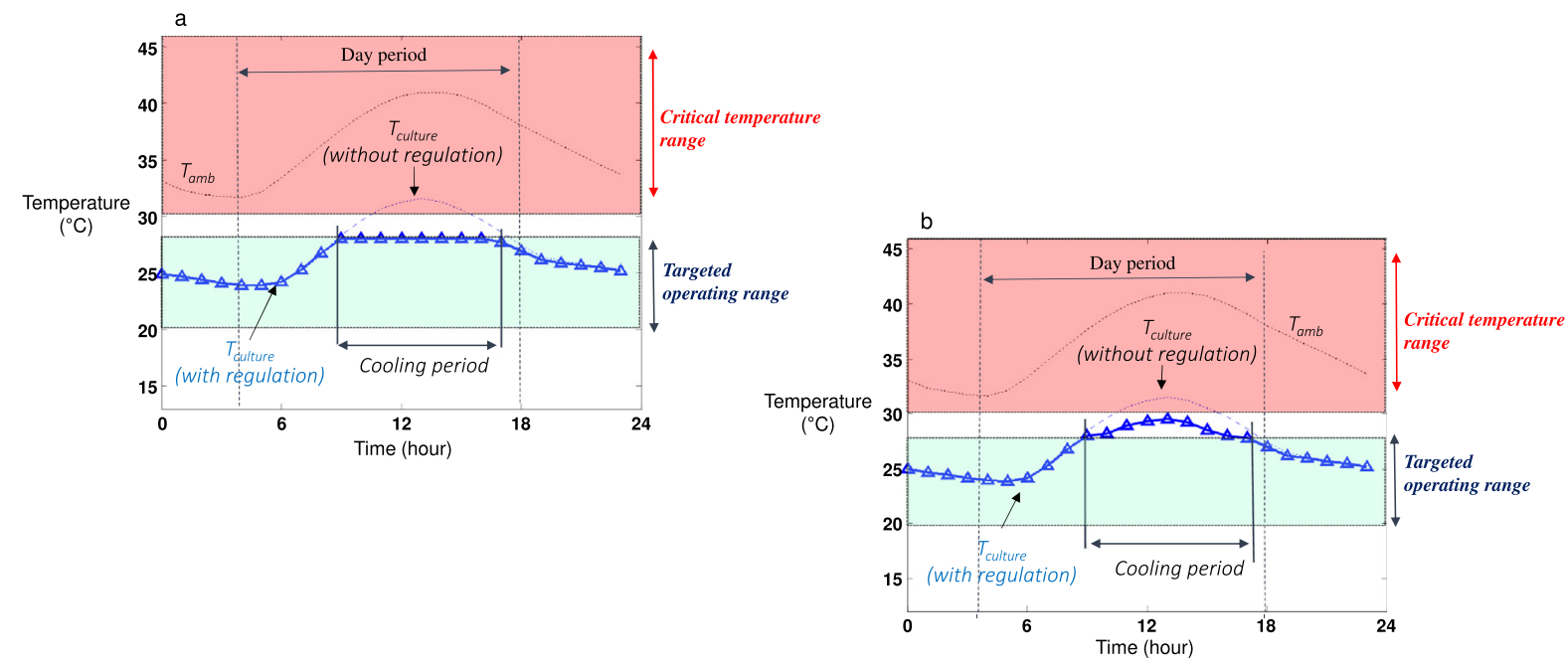

Fig. 9. Predicted daily time-course change in culture temperature with thermal regulation (triangle symbols) assuming infinite power of the thermal regulation unit (panel 9-a) and with actual power of $250 \mathrm{~W}$ per unit of cultivated surface (panel 9-b). Comparison with the temperature requirements of the temperate-climate strain. Ambient temperature and culture temperature obtained without means of thermal regulation are also added (dashed line). 
inertia of the culture system) or plastic liner thickness (due to its influence on thermal exchanges with the ground) turned out to have limited effects. An ideal regulation strategy was also tested, with culture temperature held over the day at the optimal temperature of the cultivated species $\left(25^{\circ} \mathrm{C}\right.$ for the temperate-climate species, $35^{\circ} \mathrm{C}$ for the hot-climate species). It led to a significant increase in thermal regulation energy needs compared to the case where temperature variations were accepted. Applying a set-point based on the targeted operating range as presented in the previous section resulted in a decrease of energy needs by a factor of around 2 to 5 (see cases 2 and 3 in the Table, hot-climate species). This simple result highlights one of the main differences between indoor (i.e. lab) and outdoor cultures: in most cases, outdoor microalgal culture will experience temperature regimes even if thermal regulation units are used. Whether for engineering reasons (limited power of the thermal regulation unit) or for operating cost reasons (significant increase in energy needs), maintaining constant temperature over the day will not be feasible in practice.

\subsubsection{Value of a thermal ground heat exchanger as a possible solution of optimization solution}

To conclude this study, a fairly simple engineering solution composed of a ground heat exchanger was simulated to gauge its utility value. Such a solution could easily be integrated in a semi-buried system, as used in this study. This ground heat exchanger is composed of a closed fluid loop with circulation between the culture and the ground so as to induce heat exchange between culture volume and ground sand (Fig. 10). Heat exchanges were obtained by circulating water in the closed loop, between one heat exchanger immersed in the culture medium and one heat exchanger buried in the ground sand. This simple device can then use the constant ground temperature (around $28^{\circ} \mathrm{C}$ in Qatar) as a source for thermal exchanges.

Simulations were run for a water flow rate of $\dot{m}_{\text {water }}=8.3 \mathrm{~kg} \cdot \mathrm{s}^{-1}$ (i.e. $30 \mathrm{~m}^{3} \cdot \mathrm{h}^{-1}$; other flowrates were simulated but led to similar conclusions, so only one flowrate is discussed here; see Supplementary materials for other results). The efficiency of the heat exchanger immersed in the culture medium was arbitrarily set to $\varepsilon_{\text {exch }}=0.7$. The heat exchanger buried in ground sand was assumed to have sufficiently high efficiency (i.e. surface of contact) to obtain an output temperature equal to ground temperature $\left(T_{\text {water }}=28^{\circ} \mathrm{C}\right)$. This leads to introduce the following equation in Eq. (18):

$\dot{Q}_{\text {exch }}=\dot{Q}_{\text {regul }}=\varepsilon_{\text {exch }} \dot{m}_{\text {water }} C p_{\text {water }}\left(T_{\text {water }}-T_{m}\right)$

Results are given in Fig. 11 for both the hot-climate and temperateclimate strains. For the hot-climate strain, the ground exchanger had only limited effect during summer, mainly due to ground temperature $\left(28^{\circ} \mathrm{C}\right)$ being close to culture temperature of culture, thus inducing limited exchange. A more marked effect was found for the winter period, with a roughly $7{ }^{\circ} \mathrm{C}$ increase of temperature in winter bringing temperature regimes closer to the targeted operating range. The use of such a device would then lead to an increase of productivities in winter

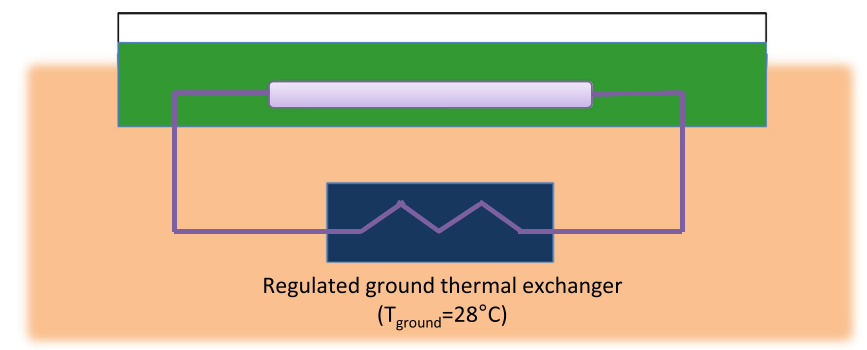

Fig. 10. Sketch of the ground exchanger used to limit overheating in summer and reach targeted operating range in winter. Heat exchanges were obtained by circulating water in the closed loop, between one heat exchanger immersed in the culture medium and another heat exchanger buried in the ground sand. periods. The corresponding values of energy exchanged with the ground were also calculated (named $Q_{\text {ground, }}$, expressed here per unit of cultivated surface). This confirms the limited power exchanged during the summer $\left(Q_{\text {ground }}=2.4 \mathrm{kWh} \cdot \mathrm{day}^{-1} \cdot \mathrm{m}^{-2}\right)$ but with a larger effect as a heating source in the winter period $\left(Q_{\text {ground }}=13.1 \mathrm{kWh} \cdot\right.$ day $\left.^{-1} \cdot \mathrm{m}^{-2}\right)$.

Contrary to use with the hot-climate strain, the ground exchanger was found to be useful as a solution for containing summer-season overheating with the temperate-climate strain. In this case, ground temperature $\left(28^{\circ} \mathrm{C}\right)$ was close to temperate-climate strain's temperature requirements $\left(20-28^{\circ} \mathrm{C}\right)$. The energy exchanged here was moderate $\left(Q_{\text {ground }}=-1.33 \mathrm{kWh} \cdot \mathrm{day}^{-1} \cdot \mathrm{m}^{-2}\right)$ yet sufficient to cool the culture down to temperature below the critical regime, which was not reached.

For the winter season, the ground exchange heated the culture volume, as for the hot-climate species, but the energy exchanged proved sufficient to reach the targeted operating range $\left(Q_{\text {ground }}=3.8 \mathrm{kWh} \cdot \mathrm{day}^{-1} \cdot \mathrm{m}^{-2}\right)$ due to the lower temperature requirement of the temperate-climate strain.

As a general conclusion to this part of the study, even if a ground exchanger does not lead to ideal temperature regimes, it does offer a simple and useful solution to allow cultivation of the temperate-climate strain in desert conditions, as it can sufficiently cool the culture to avoid overheating in summer while heating the culture volume in winter to maintain culture temperature in the targeted operating range for most of the day in winter. For the hot-climate species, the utility was mainly found for the winter period, where it acts as a heat source to counter a decrease in temperature that could be too large for a hot-climate species to guarantee efficient production.

\section{Conclusion}

Temperature management issues with solar microalgal culture in harsh desert conditions were investigated through modeling. The model took into account all relevant heat transfers involved in this kind of process, like convection exchange with ambient air and cooling effects due to water evaporation. The model was validated on experimental measurements obtained in a semi-buried raceway operated in Qatar, with an average prediction error on culture medium temperature of $1.1^{\circ} \mathrm{C}$ (maximum deviation of $4^{\circ} \mathrm{C}$ ). It was then used to predict temperature cycles and related heat transfer terms for summer and winter periods, and the results were compared to the biological requirements for two typical strains, namely a hot-climate strain and a temperateclimate strain.

The thermal behavior of the culture system revealed a complex inter-dependency of the various heat transfers involved in the process, which were strongly affected by ambient conditions (solar radiation, ambient temperature, windspeed, air humidity, and more). Culture temperatures ranged between $24-31{ }^{\circ} \mathrm{C}$ in summer and $14-21{ }^{\circ} \mathrm{C}$ in winter. During summer, evaporation was found to have a strong contribution (daily evaporation of 201 per $^{2}$ of culture), leading to a significant cooling effect with temperatures around $5-7^{\circ}$ below ambient air temperature.

Resulting temperature regimes in the culture system were in agreement with the requirements of the hot-climate species for the summer period, due to its resistance to high temperatures $\left(28-40{ }^{\circ} \mathrm{C}\right)$, but not for the winter period, with cold temperatures were far below the strain's requirements (around $12{ }^{\circ} \mathrm{C}$ below the targeted range). Comparison with the temperate-climate strain led to the opposite conclusion. Winter cultures were found close to the strain's requirements $\left(20-28^{\circ} \mathrm{C}\right)$ but reached critically high temperatures $\left(>30^{\circ} \mathrm{C}\right)$ in the middle of the day, which carries a high risk of culture drift that was accentuated here by the large PFD values encountered at around noon ( $\left.>1000 \mu \mathrm{mol}_{\mathrm{h} \nu} \cdot \mathrm{m}^{-2} \cdot \mathrm{s}^{-1}\right)$.

The thermal model was then used to simulate the utility value of introducing a thermal regulation unit. Whatever the strain, we found large energy was needed to meet the biological requirements for optimized growth over the entire year. Indeed, energy for thermal 

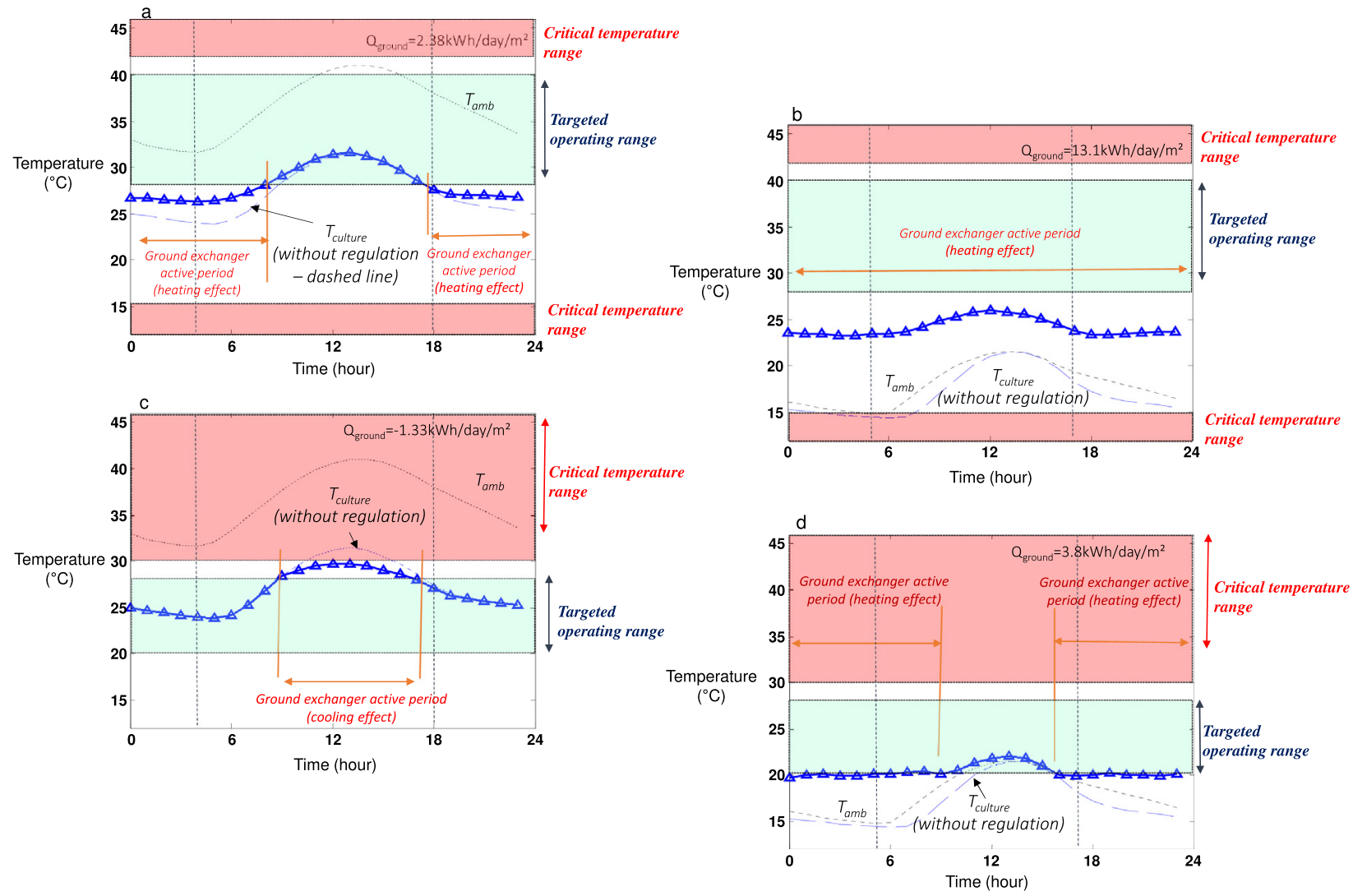

Fig. 11. Predicted daily time-course change in culture temperature with a ground heat exchanger (triangle symbols) for the hot-climate species in summer (panel 11a) and winter (panel 11-b)and for the temperate-climate species in summer (panel 11-c) and winter (panel 11-d). Ambient temperature and culture temperature obtained without means of thermal regulation are also added (dashed line).

regulation was in most cases higher than the energy absorbed from solar radiation. An extreme case was found for the hot-climate species in the winter period, where energy needs climbed higher than $20 \mathrm{kWh}$ per $\mathrm{m}^{-2}$ (around one order of magnitude higher than energy from solar radiation). This was explained by a large temperature differential between the hot-climate strain's requirements and ambient air temperature, making it necessary to heat the culture. This study highlighted a drawback of open-system culture due to the significant energy loss by water evaporation (and, to lesser extent, by convection) with ambient air, making it necessary to compensate for this loss using thermal regulation unit in winter. There was a similar energy loss issue with the temperate-climate strain, even if required a lower energy need to correct it. Finally, the only case that proved "reasonable" without introducing thermal regulation was hot-climate species cultivation in summer. This is in agreement with the current cultivation strategy retained in Qatar, which is to combine heat-resistant species with an open system for the summer-season period of the year.

This work concluded that it is practically impossible to achieve optimized biomass production year-round in the harsh desert conditions of Qatar. Even if combining a heat-resistant strain with an open system was found to be adapted to the harsh summer culture conditions (high light and temperature) due to natural cooling by water evaporation, this combination proved ineffective for the winter period: the use of an open system led to large exchange by convection with ambient air, creating it overly cold temperatures for strain requirements or, if using a thermal regulation unit, creating unrealistically high energy needed to compensate for the resulting energy loss.

Our results prompt a set of recommendations. Optimized year-round biomass production could be achievable by changing the cultivated strain over the year of operation (i.e. cultivating a hot-climate strain in summer and a temperate-climate strain in winter). Closed systems (i.e. photobioreactors) are less subject to thermal exchange with ambient air and so may prove valuable for cultivating the heat-resistant strain in winter. Note however that a tendency of closed-system photobioreactors to overheat rules out their use in the summer period, even with the hot-climate strain (i.e. as critical temperature regimes can be expected), which will almost certainly mean making a change of culture technology.

In an effort to find a simple-yet-feasible improvement solution, we investigated the utility of introducing a ground heat exchanger in the current raceway culture system. The aim was to exploit the constant year-round in-ground temperature $\left(28^{\circ} \mathrm{C}\right.$ in Qatar) to serve either as a heating or cooling source depending on period of the year and strain temperature requirements. This rather simple solution was found to efficiently limit overheating in summer, thus extending culture options to non-heat-resistant species, while providing a heat source (the ground) in the winter period that can increase culture temperature by around $7-8^{\circ} \mathrm{C}$. This would curb the negative effects of over-cold temperature on heat-resistant species. In the case of the temperate-climate strains, this rather simple solution was validated as a way to reach the optimal range of temperature for growth during the winter period.

Whatever the case and configuration, it proved particularly difficult to maintain constant (and optimal) culture temperatures in outdoor conditions. As a general result, our results confirm that microalgae will experience temperature cycle regimes in addition to diurnal light regimes. The precise effects of these parameters (and their possible coupling effects) now need to be characterized to purposefully inform the solar culture optimization process. This characterization could help define requirements for the cultivated strains and this, combined with a modeling approach as described here, would produce the tools for rational optimization of microalgal culture in outdoor conditions. 


\section{Authors contributions to the work described in the manuscript}

J. Pruvost was the main contributor of this work. His contribution was on the conception and design of the study (thermal model setting, simulation, and results analysis), drafting the article and final approval of the version to be submitted.

V. Goetz and A. Artu were involved in the thermal model setting, acquisition of data, or analysis and interpretation of data. They revise the paper critically for important intellectual content.

Das P. and H. Al Jabri were involved in the experimental validation of the thermal model, acquisition of data, or analysis and interpretation of data. They revise the paper critically for important intellectual content.

\section{Conflict of interest}

Authors declare there are no potential financial or other interests that could be perceived to influence the outcomes of the research.

\section{Statement of informed consent, human/animal rights}

No conflicts, informed consent, human or animal rights applicable.

\section{Authors' agreement}

All authors agree to authorship and submission of the manuscript for peer review.

\section{Acknowledgments} Qatar.

This work was supported by University of Nantes and University of

\section{References}

[1] C. Posten, C. Walter, Microalgal Biotechnology: Potential and Production, Walter de Gruyter \& Co., 2012.

[2] J. Pruvost, J.F. Cornet, V. Goetz, J. Legrand, Modeling dynamic functioning of rectangular photobioreactors in solar conditions, AICHE J. 57 (7) (2011) 1947-1960.

[3] J. Pruvost, J.F. Cornet, F. Le Borgne, V. Goetz, J. Legrand, Theoretical investigation of microalgae culture in the light changing conditions of solar photobioreactor production and comparison with cyanobacteria, Algal Res. 10 (2015) 87-99.

[4] A. Richmond, Handbook of Microalgal Culture: Biotechnology and Applied Phycology, Blackwell Sciences Ltd, Oxford, UK, 2004.

[5] M.A. Borowitzka, Commercial production of microalgae: ponds, tanks, and fermenters, Prog. Ind. Microbiol. 35 (1999) 313-321.

[6] V. Goetz, F. Le Borgne, J. Pruvost, G. Plantard, J. Legrand, A generic temperature model for solar photobioreactors, Chem. Eng. J. 175 (2011) 443-449.

[7] J.U. Grobbelaar, Factors governing algal growth in photobioreactors: the "open" versus "closed" debate, J. Appl. Phycol. 21 (5) (2008) 489-492.

[8] S. Hindersin, U. Hamburg (Ed.), Photosynthetic Efficiency of Microalgae and Optimization of Biomass Production in Photobioreactors, 2013.
[9] S. Hindersin, M. Leupold, M. Kerner, D. Hanelt, Key parameters for outdoor biomass production of Scenedesmus obliquus in solar tracked photobioreactors, J. Appl. Phycol. 26 (2014).

[10] A.P. Carvalho, S.O. Silva, J.M. Baptista, F.X. Malcata, Light requirements in microalgal photobioreactors: an overview of biophotonic aspects, Appl. Microbiol. Biotechnol. 89 (5) (2011) 1275-1288.

[11] S. Hindersin, M. Leupold, M. Kerner, D. Hanelt, Irradiance optimization of outdoor microalgal cultures using solar tracked photobioreactors, Bioprocess Biosyst. Eng. 36 (3) (2013) 345-355.

[12] G. Torzillo, P. Accolla, E. Pinzani, J. Masojidek, In situ monitoring of chlorophyll fluorescence to assess the synergistic effect of low temperature and high irradiance stresses in Spirulina cultures grown outdoors in photobioreactors, J. Appl. Phycol. 8 (4-5) (1996).

[13] C. Wilhelm, D. Selmar, Energy dissipation is an essential mechanism to sustain the viability of plants: the physiological limits of improved photosynthesis, J. Plant Physiol. 168 (2) (2011) 79-87.

[14] J.-F. Cornet, Calculation of optimal design and ideal productivities of volumetrically lightened photobioreactors using the constructal approach, Chem. Eng. Sci. 65 (2) (2010) 985-998.

[15] B. Perrier, C. Crampon, O. Guézet, C. Simon, F. Maire, O. Lépine, J. Pruvost, P. Lozano, O. Bernard, E. Badens, Production of a methyl ester from the microalgae Nannochloropsis grown in raceways on the French west coast, Fuel 153 (2015) 640-649.

[16] A. Muller-Feuga, M. Lemar, E. Vermel, R. Pradelles, L. Rimbaud, P. Valiorgue, Appraisal of a horizontal two-phase flow photobioreactor for industrial production of delicate microalgae species, J. Appl. Phycol. 24 (3) (2012) 349-355.

[17] M. Cuaresma, M. Janssen, E.J. Van den End, C. Vilchez, R.H. Wijffels, Luminostat operation: a tool to maximize microalgae photosynthetic efficiency in photobioreactors during the daily light cycle? Bioresour. Technol. 102 (17) (2011) $7817-7878$.

[18] M. Cuaresma, M. Janssen, C. Vilchez, R.H. Wijffels, Horizontal or vertical photobioreactors? How to improve microalgae photosynthetic efficiency, Bioresour. Technol. 102 (8) (2011) 5129-5137.

[19] A. Taleb, J. Legrand, H. Takache, S. Taha, J. Pruvost, Investigation of lipid production by nitrogen-starved Parachlorella kessleri under continuous illumination and day/night cycles for biodiesel application, J. Appl. Phycol. 30 (2017).

[20] P.M. Slegers, M.B. Lösing, R.H. Wijffels, G. van Straten, A.J.B. van Boxtel, Scenario evaluation of open pond microalgae production, Algal Res. 2 (4) (2013) 358-368.

[21] P.M. Slegers, P.J.M. van Beveren, R.H. Wijffels, G. van Straten, A.J.B. van Boxtel, Scenario analysis of large scale algae production in tubular photobioreactors, Appl. Energy 105 (2013) 395-406.

[22] P.M. Slegers, R.H. Wijffels, G. Van Straten, A.J.B. Van Boxtel, Design scenarios for flat panel photobioreactors, J. Appl. Energy 88 (2011) 3342-3353.

[23] G. Al Ghazal, T. Bounnit, M. Al Muraikhi, R. Rasheed, T. Dalgamouni, I. Saadaoui, H. Al Jabri, Qatar University culture collection: a source of biodiversity and numerous applications, QSci. Proc. 2016 (4) (2016) 47.

[24] P. Das, M.I. Thaher, M.A. Hakim, H.M. Al-Jabri, G.S. Alghasal, A comparative study of the growth of Tetraselmis sp. in large scale fixed depth and decreasing depth raceway ponds, Bioresour. Technol. 216 (2016) 114-120.

[25] E. Sartori, A critical review on equations employed for the calculation of the evaporation rate from free water surfaces, Sol. Energy 68 (2000) 77-89.

[26] R. Tang, Y. Etzion, Comparative studies on the water evaporation rate from a wetted surface and that from a free water surface, Build. Environ. 39 (2004) 77-86.

[27] W.H. McAdams, Heat Transmission, Third ed., Mc Graw-Hill, New-York, 1954.

[28] F. Le Borgne, J. Pruvost, Investigation and modeling of biomass decay rate in the dark and its potential influence on net productivity of solar photobioreactors for microalga Chlamydomonas reinhardtii and cyanobacterium Arthrospira platensis, Bioresour. Technol. 138 (2013) 271-276.

[29] A.H.H. Ali, Passive cooling of water at night in uninsulated open tank in hot and areas, Energy Convers. Manag. 48 (2007) 93-100.

[30] J.A. Duffie, W.A. Beckman, Solar engineering of thermal processes, Third edition ed., John Wiley \& Sons, New York, 2006. 